\title{
COMPARISON OF INTRATHECAL BUPIVACAINE VERSUS BUPIVACAINE AND CLONIDINE IN LOWER LIMB ORTHOPAEDIC SURGERY FOR HAEMODYNAMIC STABILITY AND POSTOPERATIVE ANALGESIA
}

\author{
Amit Jain 1 , Seema Gupta², Satyendra Uike3 ${ }^{3}$ Sarvesh Jain ${ }^{4}$ \\ ${ }^{1}$ Assistant Professor, Department of Anaesthesiology Bundelkhand Medical College, Sagar. \\ ${ }^{2}$ Assitant Professor, Department of Anaesthesiology, Chirayu Medical College, Bhopal. \\ ${ }^{3}$ Associate Professor, Department of Anaesthesiology Bundelkhand Medical College, Sagar. \\ ${ }^{4}$ Associate Professor, Department of Anaesthesiology Bundelkhand Medical College, Sagar.
}

ABSTRACT

\section{BACKGROUND}

This is a prospective randomised control trial which comprises of comparison of intrathecal bupivacaine alone versus bupivacaine and clonidine in combination in lower limb orthopaedic trauma surgery for haemodynamic stability and postoperative analgesia.

\section{MATERIALS AND METHODS}

Study was conducted in 60 ASA grade I \& II patients who were randomised into Group I (received 3.0 mL bupivacaine intrathecally and $0.5 \mathrm{~mL}$ normal saline) and Group II (patients received $3.0 \mathrm{~mL}$ bupivacaine + clonidine $0.5 \mathrm{~mL}$ ) intrathecally. Continuous monitoring of $\mathrm{HR}, \mathrm{BP}, \mathrm{RR}, \mathrm{SPO}_{2}$ was done during intraoperative \& post-operative period up to first requirement of analgesic.

\section{RESULTS}

Duration of analgesia with Bupivacaine alone was in the range of 150-310 minutes. Duration of analgesia was prolonged by addition of clonidine. Duration of analgesia in group II was in the range of 440-660 minutes. In majority of patients in group 1 it was in the range of $121-240$ minutes $(n=21,70 \%)$ while in group II, it was in the range of 481-600 minutes in majority of patients $(\mathrm{n}=18,60.00 \%)$. The difference in mean duration of analgesia among both the groups (I \& II) was statistically significant $(\mathrm{p}<0.0001)$ indicating that addition of clonidine prolongs the duration of analgesia.

\section{CONCLUSION}

Intrathecal clonidine with bupivacaine produces excellent surgical analgesia and extended analgesia in postoperative period. Clonidine increases intensity and duration of motor blockade

\section{KEYWORDS}

Spinal, Bupivacaine, Postoperative Analgesia, Clonidine, Haemodynamic.

HOW TO CITE THIS ARTICLE: Jain A, Gupta S, Uike S, et al. Comparison of intrathecal bupivacaine versus bupivacaine and clonidine in lower limb orthopaedic surgery for haemodynamic stability and postoperative analgesia. J. Evolution Med. Dent. Sci. 2017;6(21):1720-1724, DOI: 10.14260/Jemds/2017/378

\section{BACKGROUND}

Spinal anaesthesia is frequently used for lower limb orthopaedic surgeries unless contraindicated. It is low in cost, easy to practise and alleviates the complications associated with general anaesthesia like respiratory complications, nausea and vomiting. It blunts the stress response to surgery, decreases intraoperative blood loss, lowers the incidence of post-operative thromboembolic events, possibly reduces morbidity in high risk surgical patients and serves as a useful method to extend analgesia into the post-operative period. ${ }^{1}$ Besides adequate postoperative pain relief will reduce the incidence of pulmonary complication like hypoxaemia, hypercarbia, retention of secretions, atelectasis and pneumonia by allowing the patient to take deep breath and cough effectively.

Financial or Other, Competing Interest: None.

Submission 01-02-2017, Peer Review 24-02-2017,

Acceptance 04-03-2017, Published 13-03-2017.

Corresponding Author:

Dr. Amit Jain,

Chandak Vidhyasagar Colony,

Beside Bhagyoday Thirth

Khurai Road, Sagar,

Madhya Pradesh.

E-mail: tosynapse@rediffmail.com

DOI: $10.14260 /$ jemds $/ 2017 / 378$

\section{Various Methods of Postoperative Pain relief ${ }^{2}$ have been} Tried-

- Analgesics- Both narcotics and non-narcotics.

- Patient-controlled analgesia.

- Inhalation of analgesic gases and vapours.

- Acupuncture.

- Hypnosis.

- Relaxation techniques.

- Regional techniques viz. continuous epidural analgesia, nerve block, extradural and intrathecal drugs.

Attempts to find a suitable and safer agent and technique have been going on steadily. In recent times various drugs are being used via subarachnoid and epidural route to provide optimum conditions for surgery and postoperative pain relief. There have been many attempts in the past to prolong the duration of spinal anaesthesia. These developments have resulted into three approaches ${ }^{3}$, namely-

1. The use of different anaesthetic agents or their combination (Lewis 1944; Romberger 1931).

2. The use of repeated injection of the same agent (Fractional Spinal anaesthesia; Lemon 1940).

3. The use of vasoconstrictor drugs intrathecally (Heink 1905; Biberfield 1907 and Richards 1911). 
The addition of vasoconstrictor drug to the local anaesthetic solution to be injected into the subarachnoid space extends the duration of analgesia but chances of neurological complication of spinal anaesthesia is much more with its use.

Combination of opioids and local anaesthetics intrathecally has been found to be synergistic for somatic analgesia and to markedly enhance analgesic from subtherapeutic doses of spinal lignocaine and intrathecal opioids when combined with intrathecal local anaesthetics, improves the duration of sensory block.

Clonidine, an alpha-2 adrenergic agonist, has been used for many years as an antihypertensive agent. Only recently its desirable anaesthetic properties in humans are being highlighted. Numerous previous reports indicate that systemic as well as regional administration of clonidine has anaesthetic advantages which include reduction of anaesthetic requirements and prolonging duration of analgesia.4,5,6,7 There are varying reports of clinical studies regarding the effect of oral clonidine for prolongation of intraoperative analgesia during spinal anaesthesia. ${ }^{8,9,10,11,12,13}$

\section{MATERIALS AND METHODS}

Present study was conducted in our institute in a prospective randomised double blinded fashion on 60 ASA grade I \& II patients in the age group of 20-50 years. Informed consent was obtained from all patients followed by their preanaesthetic check-up where detailed history was taken, patients were physically examined and investigations like CBC, RFT, LFT, Random blood sugar, Coagulation were carried out.

\section{Exclusion Criteria}

- Infection at the site of injection.

- Patient refusal.

- Coagulopathy or other bleeding diathesis.

- Severe hypovolaemia.

- Increased intracranial pressure.

- Severe valvular heart disease.

After securing a suitable peripheral vein, all patients were administered $15 \mathrm{~mL} / \mathrm{kg}$ of Ringer's lactate solution. Baseline pulse rate, blood pressure, respiratory rate, $\mathrm{SpO}^{2}$ and ECG were recorded. The subjects were allocated to 2 groups of 30 each.

Group I- Patients in this group received $3.0 \mathrm{~mL} 0.5 \%(\mathrm{H})$ bupivacaine intrathecally and $0.5 \mathrm{~mL}$ normal saline.

Group II- Patients in this group received $3.0 \mathrm{~mL} 0.5 \%(\mathrm{H})$ bupivacaine + clonidine $0.5 \mathrm{~mL}(75 \mu \mathrm{g})$ intrathecally.

Under all aseptic precautions, lumbar puncture was performed in $\mathrm{L}_{3}-\mathrm{L}_{4}$ interspace with patients in sitting or lateral position. The drug was injected intrathecally. Immediately after the injection of the drug the patients were turned supine, all patients received oxygen at the rate of 4 $\mathrm{L} / \mathrm{min}$. via oxygen mask. Continuous monitoring of HR, BP, $\mathrm{RR}, \mathrm{SPO}_{2}$ was done during intraoperative period. Postoperative $\mathrm{HR}, \mathrm{BP}, \mathrm{RR}, \mathrm{SPO}_{2}$ was observed up to first requirement of analgesic.

\section{Time of Onset Sensory Blockade/Analgesia}

Sensory analgesia was tested by pinprick method. Absence of response to pinprick was taken as onset of sensory analgesia. The time taken from injection of drug to absence of response to pinprick was recorded as time of onset of sensory analgesia.

\section{Onset of Motor Blockade}

This was taken as the time elapsing from injection to failure to raise the lower limb on command.

\section{Degree of Motor Bock}

This was assessed by patient's movement of leg, and feet till no further change was observed. This was classified into four grades, according to criteria described by Bromage P. R. and coworkers in 1962.

HR, BP and RR were recorded every $5 \mathrm{~min}$. till $30^{\text {th }} \mathrm{min}$. and then half hourly till the completion of surgery. In postoperative period, they were recorded in immediate postoperative period and thereafter at different time intervals. This was recorded as time taken from the onset of the motor blockade to the time when the patient was able to move leg.

\section{Assessment of Postoperative Pain and Pain Relief}

All parameters were studied before shifting the patient to the ward. Strict instructions were written on paper as follows: No narcotics, analgesics and sedatives to be given. Assessment of pain was done by patients themselves, and for this assessment visual analogue scale (VAS) was used. In this study, the duration of pain relief was taken as the time from the onset of analgesia to the time when the patient demanded analgesic supplements.

\section{RESULTS}

Variation from the baseline value and the difference in pulse rate of both the groups during $1 / 2$ hour to 2 -hour duration was statistically significant $(\mathrm{p}<0.05)$. The difference in pulse rate after 2-hour duration was statistically insignificant $(p>0.05)$, suggesting that addition of clonidine had altered the pulse rate significantly for initial two-hour duration and then returned to baseline value.

Variation from the baseline value and the difference in BP of both the groups during $1 / 2$ hour to 2-hour duration was statistically significant $(\mathrm{p}<0.05)$. The difference in BP after 2 hour duration was statistically insignificant $(p>0.05)$, suggesting that addition of clonidine had altered the BP significantly for initial two-hour duration and then returned to baseline value. Variation from the baseline value and the difference in respiratory rate of both the groups during different time interval was statistically insignificant ( $p>0.05)$ dictating that addition of clonidine had not altered the respiratory rate (Table 1 ).

Onset of sensory blockade was in the range of 121-180 seconds in majority of patients $(n=18,60 \%)$ in group I and $(n=20,66.67 \%)$ in group II. The difference in mean onset of analgesia among both the groups was statistically insignificant $(\mathrm{p}>0.05)$, indicating that addition of clonidine had not shortened the onset of sensory blockade. (Table 2).

Onset of motor blockade was in the range of 241-300 seconds in majority of patients in both groups $(n=17$, $56.67 \%)$ in group I and $(n=17,56.67 \%)$ in group II. The 
difference in mean onset of motor blockade among both the groups was insignificant statistically $(p>0.05)$ indicating that addition of clonidine had not shortened the onset of motor blockade. (Table 3).

Mean VAS score was significantly lower in group II as compared to group I. The difference between the mean VAS score at different times, among both the groups, was statistically significant $(\mathrm{P}<0.001)$. (Table 4$)$.

Majority of patients in group I $(n=19,63.33 \%)$ had duration of motor blockade in the range of 121-180 minutes, while only $2(6.67 \%)$ patients in group II had motor blockade within this range. In group II, majority of patients had duration of motor blockade in the range of 241-300 (50\%). The difference in the mean duration of motor blockade among both the groups was significant statistically $(\mathrm{p}<0.001)$ indicating that addition of clonidine prolongs the duration of motor blockade. (Table 5).
Duration of analgesia with bupivacaine alone was in the range of 150-310 minutes. Duration of analgesia was prolonged by addition of clonidine. Duration of analgesia in group II was in the range of 440-660 minutes. In majority of patients in group I it was in the range of 121-240 minutes $(\mathrm{n}=21,70 \%)$ while in group II, it was in the range of 481-600 minutes in majority of patients $(n=18,60.00 \%)$. The difference in mean duration of analgesia among both the groups (I \& II) was statistically significant $(p<0.0001)$ indicating that addition of clonidine prolongs the duration of analgesia. (Table 6).

When we compare demographic data then majority of patients were in age group 31-40 years in both groups. This comprised of $53 \%$ patients out of 60 patients of this study. Mean age in group I was $34.93 \pm 7.56$ years and in group II, it was $35.33 \pm 7.44$ years. Difference between both groups was statistically insignificant $(\mathrm{P}>0.05)$ (Table 7).

\begin{tabular}{|c|c|c|c|c|c|c|}
\hline & \multicolumn{2}{|c|}{$\begin{array}{c}\text { Variation of Pulse Rate } \\
\text { (Per minute) }\end{array}$} & \multicolumn{2}{c|}{ Variation of BP (mmHg) } & $\begin{array}{c}\text { Variation in Respiratory Rate } \\
\text { (Per minute) }\end{array}$ \\
\hline Period of Observation & Group I & Group II & Group I & Group II & Group I & Group II \\
\hline Preoperative & $84.66 \pm 9.45$ & $83.86 \pm 9.42$ & $126.67 \pm 12.13$ & $125 \pm 12.52$ & $16.06 \pm 0.837$ & $16.47 \pm 0.98$ \\
\hline $1 / 2$ hour & $83.40 \pm 9.44$ & $69.73 \pm 7.60$ & $114 . \pm 11.80$ & $107.4 \pm 10.63$ & $16.63 \pm 0.67$ & $16.60 \pm 0.88$ \\
\hline 1 hour & $84.86 \pm 6.39$ & $72.06 \pm 7.22$ & $117.33 \pm 11.46$ & $109.66 \pm 10.25$ & $16.57 \pm 0.56$ & $16.07 \pm 0.67$ \\
\hline 2 hours & $84.53 \pm 6.38$ & $79.86 \pm 8.28$ & $120.33 \pm 9.99$ & $110.33 \pm 9.44$ & $16.73 \pm 0.66$ & $16.33 \pm 0.67$ \\
\hline 4 hours & $83.60 \pm 7.26$ & $81.33 \pm 8.39$ & $121.33 \pm 8.19$ & $115.67 \pm 7.74$ & $16.70 \pm 0.59$ & $16.37 \pm 0.62$ \\
\hline 6 hours & $83.93 \pm 7.03$ & $81.60 \pm 7.94$ & $123.33 \pm 8.44$ & $118.33 \pm 9.49$ & $16.67 \pm 0.67$ & $16.33 \pm 0.66$ \\
\hline 8 hours & $84.53 \pm 6.47$ & $82.73 \pm 7.32$ & $124.66 \pm 8.99$ & $122.66 \pm 8.69$ & - & - \\
\hline
\end{tabular}

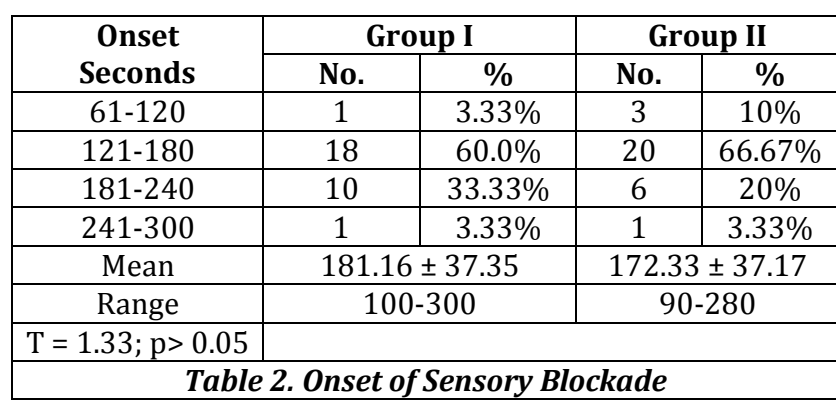

\begin{tabular}{|c|c|c|c|c|}
\hline \multirow{2}{*}{ Onset Seconds } & \multicolumn{2}{|c|}{ Group I } & \multicolumn{2}{c|}{ Group II } \\
\cline { 2 - 5 } & No. & $\mathbf{\%}$ & No. & \% \\
\hline $121-180$ & 2. & 6.67 & 2 & 6.67 \\
\hline $181-240$ & 1 & 3.33 & 4 & 13.33 \\
\hline $241-300$ & 17 & 56.67 & 17 & 56.67 \\
\hline $301-360$ & 5 & 16.67 & 5 & 16.67 \\
\hline $361-420$ & 5 & 16.67 & 2 & 6.66 \\
\hline Mean & \multicolumn{3}{|c|}{$302 \pm 57.97$} & $288.3 \pm 53.84$ \\
\hline Range & \multicolumn{3}{|c|}{$180-420$} & \multicolumn{2}{c|}{$180-400$} \\
\hline T = 0.94; p>0.05 & \multicolumn{3}{|c|}{ Table 3. Onset of Motor Blockade } \\
\hline \multicolumn{3}{|c}{}
\end{tabular}

\begin{tabular}{|c|c|c|}
\hline Duration in Hours & Group I & Group II \\
\hline 2 hours & $15.83 \pm 5.58$ & $0 \pm 0$ \\
\hline 4 hours & $47.83 \pm 6.61$ & $1.67 \pm 2.50$ \\
\hline 6 hours & $73 \pm 7.83$ & $7.167 \pm 8.97$ \\
\hline 8 hours & $83.86 \pm 5.45$ & $18.83 \pm 16.01$ \\
\hline \multicolumn{2}{|c|}{ Table 4. Mean Visual Analogue Scale (VAS) Score } \\
\hline
\end{tabular}

\begin{tabular}{|c|c|c|c|c|}
\hline \multirow{2}{*}{$\begin{array}{c}\text { Duration } \\
\text { (Minutes) }\end{array}$} & \multicolumn{2}{|c|}{ Group I } & \multicolumn{2}{c|}{ Group II } \\
\cline { 2 - 5 } & No. & $\mathbf{\%}$ & No. & \% \\
\hline $61-120$ & 1 & $3.33 \%$ & 0 & 0 \\
\hline $121-180$ & 19 & $63.33 \%$ & 2 & $6.67 \%$ \\
\hline $181-240$ & 10 & $33.33 \%$ & 13 & $43.33 \%$ \\
\hline $241-300$ & 0 & 0 & 15 & $50 \%$ \\
\hline Range & $150-200$ & & $180-300$ & $244 \pm 32.55$ \\
\hline Mean & $167.5 \pm 23.44$ & \multicolumn{4}{|l|}{} \\
\hline T =10.44; p >0.0001 & \multicolumn{6}{|l}{ Table 5. Duration of Motor Blockade } \\
\hline
\end{tabular}

\begin{tabular}{|c|c|c|c|c|}
\hline \multirow{2}{*}{$\begin{array}{c}\text { Duration } \\
\text { (Minutes) }\end{array}$} & \multicolumn{2}{|c|}{ Group I } & \multicolumn{2}{c|}{ Group II } \\
\cline { 2 - 5 } & No. & $\mathbf{\%}$ & No. & $\mathbf{\%}$ \\
\hline $121-240$ & 21 & $70 \%$ & 0 & 0 \\
\hline $241-360$ & 9 & $30 \%$ & 0 & $0 \%$ \\
\hline $361-480$ & 0 & 0 & 03 & $10 \%$ \\
\hline $481-600$ & 0 & 0 & 18 & $60 \%$ \\
\hline $601-720$ & 0 & 0 & 9 & $30 \%$ \\
\hline Range & \multicolumn{2}{|c|}{$150-310$} & $440-660$ \\
\hline Mean & $219 \pm 38.45$ & $574 \pm 63.17$ \\
\hline $\mathrm{T}=26.29 ; \mathrm{p}<0.0001$ & Table 6. Duration of Analgesia \\
\hline \multicolumn{6}{|r}{} \\
\hline
\end{tabular}

\begin{tabular}{|c|c|c|c|c|c|c|}
\hline \multirow{2}{*}{ Age Yrs. } & \multicolumn{3}{|c|}{ Group I } & \multicolumn{3}{c|}{ Group II } \\
\cline { 2 - 7 } & Male & Female & Total & Male & Female & Total \\
\hline $21-30$ & 5 & 4 & 9 & 4 & 2 & 6 \\
\hline $31-40$ & 8 & 7 & 15 & 10 & 7 & 17 \\
\hline $41-50$ & 2 & 4 & 6 & 3 & 4 & 7 \\
\hline Total & $\mathbf{1 5}$ & $\mathbf{1 5}$ & $\mathbf{3 0}$ & $\mathbf{1 7}$ & $\mathbf{1 3}$ & $\mathbf{3 0}$ \\
\hline $\begin{array}{c}\text { Mean } \\
\text { Age } \pm \text { SD }\end{array}$ & \multicolumn{3}{|c|}{$34.4 \pm 7.56$} & \multicolumn{3}{c|}{$35.33 \pm 7.44$} \\
\hline \multicolumn{3}{|c|}{ Table 7. Age and Sex Wise Distribution } \\
\hline
\end{tabular}




\section{DISCUSSION}

The difference in the onset of analgesia was insignificant statistically $(p>0.05)$ indicating that clonidine had no effect on the onset of analgesia.

In this study, the onset of motor blockade was tested by method described by Bromage PR in 1962. The mean onset of motor blockade recorded in this study was $302.0 \pm 57.97$ in group I and $288.3 \pm 53.84$ in group II. The difference was found to be statistically insignificant indicating that clonidine has no influence when added to local anaesthetics in respect to onset of sensory and motor blockade.

Gordhet al (1983) evaluated the analgesia effect of clonidine in man. They reported that IV injection of clonidine relieves postoperative pain. The level of sensory blockade in group I and group II was statistically insignificant. There was no significant difference of maximum level of analgesia between two groups. In both the groups, all the patients had grade III motor blockade suggesting that clonidine does not have any effect on grade of motor blockade.

Mean duration of motor blockade was $167.5 \pm 23.44$ minutes in group I and $244 \pm 32.55$ minutes in group II. The difference between both the groups was statistically significant $(\mathrm{p}<0.01)$. Kumar P. 1993, Racle et al, ${ }^{14}$ Sites BD 2003, Jain $\mathrm{P} N$ et al $2003^{15}$ also found prolonged motor blockade in the intrathecal clonidine group compared to control group ( $\mathrm{p}<0.01)$.

The mean visual analogue scale score in group II (which received intrathecal clonidine) was found to be significantly less as compared to those in group I $(\mathrm{p}<0.0001)$. Chiari, Lorber et al, 1999;16 Dobrydnjov J Axelsson et al, 2003;17 Stephan Strebel et al 200418 found that intrathecal clonidine caused significant decrease in VAS score.

Mean duration of analgesia was $213 \pm 38.45$ minutes in group I and $574 \pm 63.12$ minutes in groups II. The difference is significant statistically $(\mathrm{p}<0.0001)$. It shows that addition of clonidine to intrathecal bupivacaine prolongs the duration of analgesia. P N Jain, Gehdoo RP Priya et al ${ }^{19}$ (2003) have reported that when intrathecal clonidine $75 \mu \mathrm{g}$ was injected with bupivacaine for genitourinary surgery, the duration of analgesia was $10.6 \pm 2.1$ hours in clonidine group as compared to $3.6 \pm 0.6$ hours in bupivacaine group. Strebel et al $(2004)^{18}$ have reported that $75 \mu \mathrm{g}$ intrathecal clonidine with bupivacaine for orthopaedic surgery, the time of regression for spinal anaesthesia below L1 was $325 \pm 69 \mathrm{~min}$. as compared to bupivacaine group that was $288 \pm 62 \mathrm{~min}$. $(\mathrm{p}<0.05)$.

Addition of clonidine has improved sedation in group II which is often a desirable effect during the intra and early post-operative period. The mean pulse rate/minute before intrathecal injection were $84.67 \pm 9.45$ and $83.86 \pm 9.42$ in group I and group II respectively. The difference was statistically significant from $1 / 2$ hour to 2 hours and then the difference between both groups was statistically insignificant ( $p>0.05$ ). It suggests that intrathecal clonidine causes fall in pulse rate that mainly occurs in initial 2 hours duration and then returned to baseline value.

It suggests that fall in BP caused by clonidine mainly occurred in initial 2 hours and came back to baseline value. Eliv et al 2008, Chiari et al,16 PN Jain et al found that intrathecal clonidine caused dose-dependent hypotension and was well controlled by ephedrine. The difference between pre-injection value and after giving intrathecal injection at different period of time in both the groups was found to be statistically insignificant $(p>0.05)$ and the difference between both the groups at different time interval was also insignificant. ( $p>0.05)$.

Though incidence of hypotension and bradycardia were higher in clonidine, it was statistically insignificant. Incidence of hypotension was well controlled by ephedrine.

\section{CONCLUSION}

1. Intrathecal clonidine with bupivacaine $0.5 \%$ heavy produces excellent surgical analgesia and an extended analgesia in postoperative period.

2. Intrathecal clonidine with bupivacaine $0.5 \%$ heavy increases intensity and duration of motor blockade.

3. This method can be considered as a method of preemptive analgesia, which avoids the multiple pricks for analgesia in the immediate postoperative period.

4. Clonidine treated patients were sedated and comfortable throughout the surgical procedure, thus avoiding any other medication.

5. Intrathecal clonidine caused clinically significant reduction in pulse rate and mean blood pressure intraoperatively which returned to baseline value after 2 hours.

Thus, on the basis of our study, we advocate the use of injection clonidine $75 \mu \mathrm{g}$ with injection bupivacaine $0.5 \%$ intrathecally for prolonged postoperative analgesia in lower limb surgeries with minimum side effects and better patient comfort.

\section{REFERENCES}

[1] Bernards CM. Epidural and spinal anaesthesia in clinical anaesthesia. Edited by Barash PG. Philadelphia: Lippincott Williams \& Wilkins 2009:92754.

[2] Miller RD. Anaesthesia. $6^{\text {th }}$ edn. Edited by Miller RD. Philadelphia, Elsevier, Churchill, Livingstone 2005:3,198.

[3] Lee JA, Atkinson RS, Watt MJ. Sir Robert Macintosh's lumber puncture and spinal analgesia. $5^{\text {th }}$ edn. Churchill Livingstone, New York 1985:282.

[4] Bloor BC, Flacke WE. Reduction in halothane anesthetic requirement by clonidine, an alphaadrenergic agonist. Anaesth Analg 1982;61(9):741-5.

[5] Ghignone M, Noe C, Calvillo 0, et al. Anaesthesia for ophthalmic surgery in the elderly: the effects of clonidine on intraocular pressure, perioperative haemodynamics and anaesthetic requirements. Anaesthesiology 1988;68:707-16.

[6] Gordh T. Epidural clonidine for treatment of postoperative pain after thoracotomy. A double-blind placebo-controlled study. Acta Anaesth Scand 1988;32(8):702-9.

[7] Longnecker DE. Alpine anaesthesia: can pretreatment with clonidine decrease the peaks and valleys? Anaesthesiology 1987;67(1):1-2.

[8] Kirno K, Lundin S, Elam M. Epidural clonidine depresses sympathetic nerve activity in humans by a supraspinal mechanism. Anaesthesiology 1993;78(6):1021-7. 
[9] Mendez R, Eisenach JC, Kashtan K. Epidural clonidine analgesia after cesarean section. Anaesthesiology 1990;73(5):848-52.

[10] Motsh J, Graber E, Ludwig K. Addition of clonidine enhances postoperative analgesia from epidural morphine: a double-blind study. Anaesthesiology 1990;73(6):1067-73.

[11] Nishikawa T, Dohi S. Clinical evaluation of clonidine added to lidocaine solution for epidural anaesthesia. Anaesthesiology 1990;73(5):853-9.

[12] Liu S, Chiu AA, Neal JM, et al. Oral clonidine prolongs lidocaine spinal anaesthesia in human volunteers. Anaesthesiology 1995;82(6):1353-9.

[13] Ota K, Namiki A, Ujike Y, et al. Prolongation of tetracaine spinal anaesthesia by oral clonidine. Anaesth Analg 1992;75(2):262-4.

[14] Racle JP, Benkhadra A, Poy JY, et al. Prolongation of isobaric bupivacaine spinal anaesthesia with epinephrine and clonidine for hip surgery in the elderly. Anaesth Analg 1987;66(5):442-6.
[15] Jain PN, Gehdoo RP, Priya V, et al. A prospective study of intrathecal clonidine for postoperative pain relief. Indpain 2003;17(2):12-4.

[16] Chiari A, Lorber C, Eisenach JC, et al. Analgesia and haemodymanic effects of intrathecal clonidine as the sole analgesia agent during first stage of labour: a dose response study. Anaesthesiology 1999;91(2):388-96.

[17] Dobrydnjov I, Axelsson K, Thorn SE, et al. Clonidine combined with small dose bupivacaine during spinal anaesthesia for inguinal herniorrhaphy: a randomized double blinded study. Anaesth Analg 2003;96(5):1496-503.

[18] Strebel S, Gurzeler JA, Schneider MC, et al. Small-dose intrathecal clonidine and isobaric bupivacaine for orthopaedic surgery: a dose-response study. Anaesth Analg 2004;99(4):1231-8.

[19] Jain PN, Gehdoo RP, Priya V. Study of intrathecal clonidine for postoperative pain relief. Indpain 2003;17(2):1233-36. 